\title{
Retrospective Investigation of Treatment Protocols for Drug Poisonings Admitted to Emergency Department
}

\author{
Selcuk Eren Canakci', Bekir Dagli', Kenan Ahmet Turkdogan'2, Ayhan Akoz ${ }^{2}$, Mucahit Avcil', Ali Duman ${ }^{2}$
}

\footnotetext{
${ }^{1}$ Mustafa Kalemli Tavşanlı State Hospital, Emergency Service, Kütahya, Turkey

${ }^{2}$ Adnan Menderes University, Faculty of Medicine, Department of Emergency Medicine, Aydin, Turkey
}

Corresponding Author:

Selcuk Eren Canakci

Kütahya Doç. Dr. Mustafa Kalemli

Tavşanlı State Hospital,

Emergency Service, Kütahya, TURKEY

E-mail: selcuk.eren.canakci@gmail.com
Received: 05.02.2018,

Accepted: 03.03.2018

DOI: $10.5799 /$ jcei.413055

\section{A B S T R A C T}

Objective: The purpose of this study was to investigate the demographic and etiologic features of acute poisoning cases, the toxic substances which cause the poisonings and their properties, laboratory findings and clinical features retrospectively and to show what could be the precautions to be taken.

Patients and Methods: Total of 483 patients, who were admitted to emergency department with drug poisoning within 3 years and whose information was available were taken into this retrospective study. The patients' age, sex, date of admission to hospital, duration of hospitalization in emergency department and intensive care unit, clinical outcomes, agents and amounts of drugs taken, applied antidote and extracorporeal treatments, laboratory values of cases were examined.

Results: 179 (37,1\%) of the cases were followed up for an average of 3,21 $\pm 4,5$ days in the intensive care unit and 304 (62,9\%) patients were followed up for an average of 2,1 \pm 2 days in the observation unit of the emergency department. When the lipophilicity of poisoning drugs were examined, in 191 (39.5\%) patients only lipophilic, in 100 (20.7\%) patients lipophilic and additional substance, in 83 (17.2\%) patients only hydrophilic and in 109 (22.6\%) patients hydrophilic drug and additional substance was found. Extracorporeal treatment was applied to 14 patients. Our mortality rate was found $0.62 \%$.

Conclusion: Early intervention in poisonings is life-saving. Supportive therapies, antidotes and extracorporal techniques may reduce mortality, but toxicological guidelines may be needed to guide clinicians in more extensive studies.

Key Words: intoxication, extracorporal, mortality, duration of hospitalization, lipid

\section{INTRODUCTION}

Poisoning has been one of the major problems that have been closely related to societies since ancient times [1]. The toxic response resulting from the exposure depends on the physical properties of the agent, on the way of entry into the body and on the individual's propensity for the substance [2]. Poisoning is the most common cause of non-traumatic coma in admission to emergency services among young adults under age $35[1,3]$. According to the 2015 Annual Report of American Association of Poison Control Centers (AAPCC), $92 \%$ of deaths from poisoning are 20 years of age or older [4]. In developed countries, the annual incidence of poisonings due to suicide and accidents varies between $0.02-0.93 \%$ [5-7] and continues to increase every year in the world. It has been reported that poisoning cases applied to emergency services in our country constitute $0.46-1.57 \%$ of all cases [7].

Factors that lead to poisoning may vary according to region, community traditions and customs, level of education and seasons [8]. In developed countries, drug poisoning is the forerunner, while in developing countries such as India and Thailand, pesticide and home products poisoning are the leading causes $[9,10]$. The causes of poisoning can vary from country to country, from region to region in a country, from year to year in a region. For this reason, the poisoning-related characteristics of each 
country and even each region should be determined, and necessary precautions should be taken according to the risks and threats.

Acute poisonings can produce different clinical tables with the drug used, the type of ingestion, the duration of exposure and many factors related to the patient (age, sex, additional disease, etc.) [11]. About 5 to $30 \%$ of the capacity of multidisciplinary intensive care units is used for poisoning cases $[1,3,7]$. The most common poisoning causes are medicinal products, pleasureinducing substances, industrial and agricultural toxic substances [1].

In this retrospective study, we evaluated the characteristics of acute poisoning cases admitted to our Emergency Department, the duration of intensive care unit and hospital stay, the clinical conditions during the hospitalization period, types of intoxications, laboratory findings, lipophilicity of received substances, additional treatments (IV lipid therapy, hemodialysis, hemoperfusion, hemofiltration, plasmapheresis), clinical outcome, and whether these factors are associated with mortality in the context of the literature.

\section{PATIENTS AND METHODS}

Our study was approved by the local ethics committee's decision dated 09.02.2017 numbered 53043469-050.04.04. Between 01/09/2013-01/09/2016, 535 people who were poisoned by taking medicines admitted to our emergency department, the information of 483 people were gathered and included in the study.

In the case report form, the socio-demographic characteristics of the patients, application dates, name and surnames, file numbers, duration of intensive care and hospital stay, clinical results, poisoning substance and amount, $\log D$ values of the substances, other substances which can causes poisoning, antidote and amount, extracorporal techniques, complete blood count, biochemistry, blood gas analysis and coagulation tests from the time of aplication were retrospectively recorded.

\section{Statistical Analysis}

The datas were assessed by the statistical package program named SPSS Statistics for Windows Version 18.0. Chicago: SPSS Inc. Values were given as mean and standard deviation and $\mathrm{p}$ $<0.05$ was considered significant. The Kolmogorov Smirnov test was used to check whether the data fit the normal distribution. Mann Whitney U test was used for statistical comparisons for ineligible variables with normal distribution, and descriptive statistics were presented in both mean and median (25-75 percentile) format. In statistical comparisons for categorical variables, chisquare test was used, and descriptive statistics were expressed as frequency (\%).

\section{RESULTS}

When we look at the genders of 483 cases, $64.2 \%(n=310)$ were female, and $35.8 \%(n=173)$ were male. The mean age was found $33.4 \pm 12.48(37.58 \pm 14.66$ for males and $31.35 \pm 10.56$ for females). The difference between male and female average ages was found statistically significant $(\mathrm{p}<0.001)$.

179 (37.1\%) of the 483 patients were followed up for an average of $3.21 \pm 4.5$ days in the intensive care unit and 304 (62.9\%) patients were followed up for an average of $2.1 \pm 2$ days in the observation unit of the emergency department. The correlation between the duration of hospitalization and the lactate level at admission was statistically significant $(r=0.422, \mathrm{p}=0.006)$.

When the poisoning drug groups were classified; antidepressants were found in 87 patients (18\%), paracetamols were found in 70 patients (14.5\%), NSAID's were found in 59 patients (12.2\%) and antipsychotic drugs were found in 53 patients (11\%) in 483 cases (Table 1). When antidepressants are classified as the cause of poisoning; SSRIs were the most frequent group with 52 (58.4\%) cases.

In male patients; $22(12.7 \%)$ cases were poisoned by agricultural chemicals and $21(12.1 \%)$ cases were poisoned by narcotics. In female patients; 7 (2.3\%) cases were poisoned by agricultural chemicals and $2(0.6 \%)$ cases were poisoned by narcotics. The use of SSRIs was also found to be higher in females than in males.

Table 2 shows the total length of hospitalizations, duration of stay in the service unit and intensive care unit according to the drug groups to which the patients were poisoned.

When the lipophilicity of poisoning drugs is examined; 191 cases (39.5\%) were poisoned with lipophilic drugs and 100 cases (20.7\%) were exposed to lipophilic and additive agents (Table $3)$.

The total number of patients receiving extracorporeal treatment was 14. Six of them received hemodialysis, two received plasmapheresis, one received hemofiltration, and five received hemoperfusion tratment (Table 4).

In a case of poisoning with organophosphates, the blood glucose level was $441 \mathrm{mg} / \mathrm{dL}$ at time of admission and resulted in exitus.

Five (35.7\%) patients were poisoned with methyl alcohol, 3 (21.4\%) with antiepileptic drugs, $2(14.3 \%)$ with organophosphates, $2(14.3 \%)$ with antipsychotics, $1(7.1 \%)$ narcotics and $1(7.1 \%)$ was poisoned with dopaminergic antidepressant drugs from 14 patients who were treated with extracorporeal treatment. Twelve of these 14 patients (85.7\%) were followed up in intensive care unit. A methyl alcohol and an organophosphate poisoning case resulted in exitus.

Reasons of poisonings that result in exitus consists of a methyl alcohol, a carbamate-containing and an organophosphate-containing agent. Methyl alcohol poisoning case received hemoperfusion and organophosphate poisoning case received plasmapheresis treatments. In the case of organophosphate poisoning treated with plasmapheresis, IV lipid therapy was also applied. It has been observed that all exitus cases were poisoned by the single substance. 
Treatment Protocols for Drug Poisonings

Table 1. Groups and frequency of drugs causing poisoning

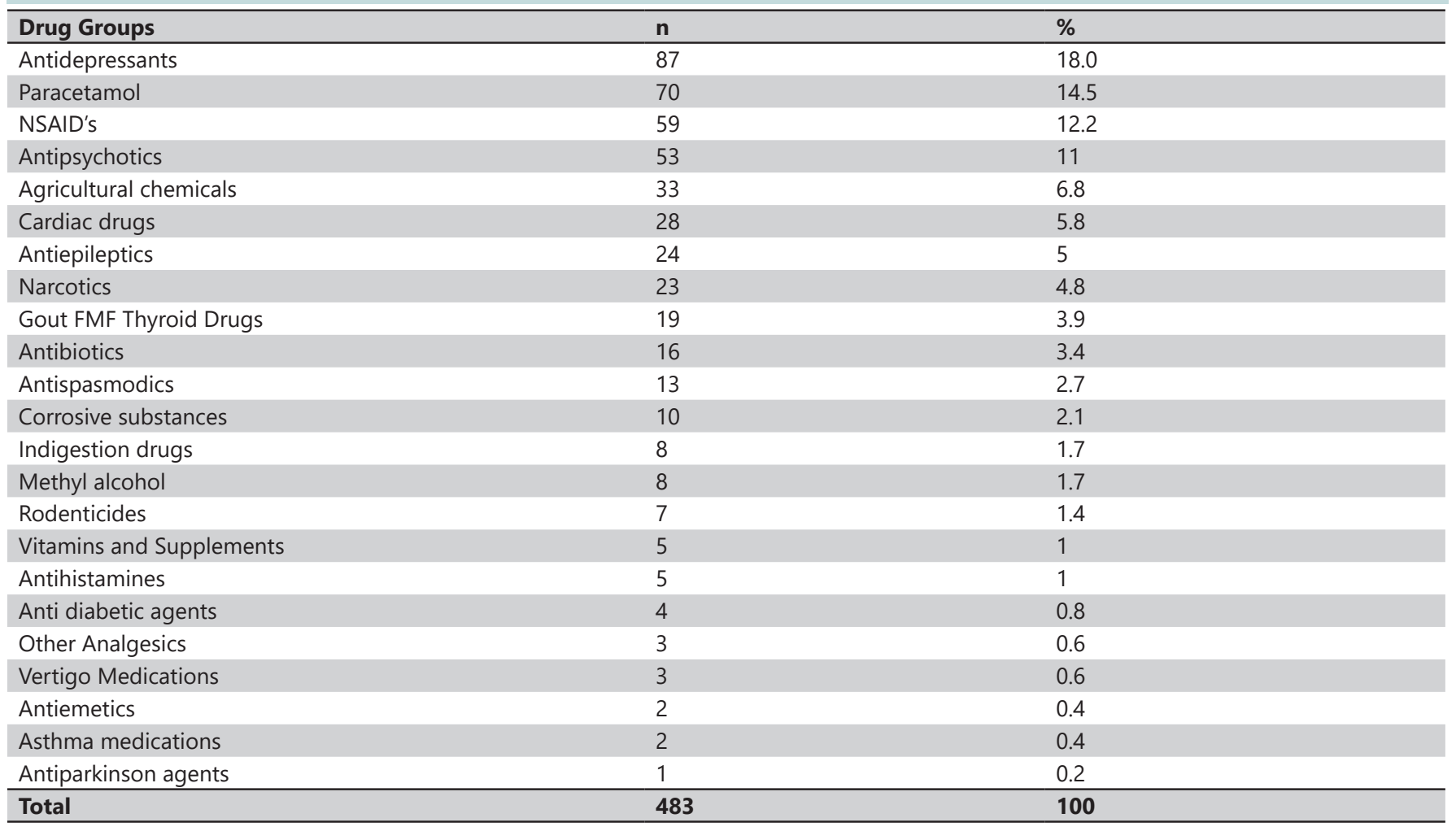

Table 2. Total Hospitalization / Intensive Care / Service Periods by Group of Poisoning Drugs

\begin{tabular}{|c|c|c|c|}
\hline Drug groups & Total hospitalization (days) & Intensive Care Unit (days) & Service (days) \\
\hline Paracetamol & $2.3 \pm 0.84$ & $0.8 \pm 1.1$ & $1.5 \pm 0.9$ \\
\hline NSAIDs & $1.9 \pm 0.7$ & $0.4 \pm 0.9$ & $1.5 \pm 0.7$ \\
\hline Gout FMF Thyroid drugs & $2.9 \pm 1.5$ & $1.0 \pm 1.2$ & $2.0 \pm 1.8$ \\
\hline Corrosive substances & $1.9 \pm 0.6$ & - & $1.9 \pm 0.6$ \\
\hline Antibiotics & $1.9 \pm 0.68$ & $0.4 \pm 0.9$ & $1.6 \pm 0.7$ \\
\hline Narcotics & $2.8 \pm 1.5$ & $1.7 \pm 1.8$ & $1.1 \pm 1.0$ \\
\hline Other analgesics & $1.7 \pm 0.6$ & $0.3 \pm 0.6$ & $1.3 \pm 1.1$ \\
\hline Antiepileptics & $3.1 \pm 1.7$ & $1.8 \pm 1.7$ & $1.3 \pm 1.1$ \\
\hline Rodenticides & $9.7 \pm 14.3$ & $4.4 \pm 5.0$ & $5.3 \pm 9.7$ \\
\hline Vitamines & $1.7 \pm 0.6$ & - & $1.7 \pm 0.6$ \\
\hline Indigestion drugs & $1.75 \pm 0.7$ & $0.9 \pm 1.1$ & $0.9 \pm 0.6$ \\
\hline Methanol & $11.2 \pm 17.4$ & $10.0 \pm 18.0$ & $1.2 \pm 1.6$ \\
\hline Antiemetics & 1.0 & $0.5 \pm 0.7$ & $0.5 \pm 0.7$ \\
\hline SARIs & $2.5 \pm 0.7$ & - & $2.5 \pm 0.7$ \\
\hline Vertigo Medications & $2.3 \pm 1.1$ & $1.0 \pm 1.7$ & $1.3 \pm 1.5$ \\
\hline Antiparkinson agents & 1.0 & - & $1.0 \pm 0.2$ \\
\hline Antidepressants & $2.8 \pm 3.3$ & $0.9 \pm 1.3$ & $1.9 \pm 3.4$ \\
\hline Agricultural chemicals & $4.0 \pm 3.8$ & $2.4 \pm 4.0$ & $1.5 \pm 1.8$ \\
\hline Cardiac drugs & $2.3 \pm 0.6$ & $0.6 \pm 1.0$ & $1.6 \pm 0.9$ \\
\hline
\end{tabular}

SARIs: Serotonin antagonist and reuptake inhibitors 
Treatment Protocols for Drug Poisonings

Table 3. Locations and total hospitalization durations of the cases according to the lipophilicity of the active substances

\section{n Service (days) n (\%) Intensive Care Unit (days) n (\%) Total hospitalization (days)}

\begin{tabular}{lcccc}
\hline Lipophilic drug & 191 & $113(59.2)$ & $78(40.8)$ & $3.2 \pm 4.9$ \\
$\begin{array}{l}\text { Lipophilic drug and } \\
\text { additive agents }\end{array}$ & 100 & $61(61)$ & $39(39)$ & $3.0 \pm 3.6$ \\
$\begin{array}{l}\text { Hydrophilic drug } \\
\begin{array}{l}\text { Hydrophilic drug and } \\
\text { additive agents }\end{array}\end{array}$ & 83 & $60(72.3)$ & $23(27.7)$ & $39(35.8)$ \\
\hline
\end{tabular}

Table 4. Analysis of applied extracorporeal treatments

\begin{tabular}{|c|c|c|c|c|}
\hline Extracorporeal treatments & Number of cases & $\%$ & $\begin{array}{l}\text { Number of Patients } \\
\text { with IV Lipid Treatment }\end{array}$ & Cases (n) / Main Active Substance \\
\hline Hemodialysis & 6 & 42.85 & 1 & $\begin{array}{l}5 \text { Methyl alcohol } \\
1 \text { Antipsychotics }\end{array}$ \\
\hline Hemoperfusion & 5 & 35.72 & 3 & $\begin{array}{l}2 \text { Antiepileptics } \\
1 \text { Antipsychotics } \\
1 \text { Antidepresssants } \\
1 \text { Methyl alcohol }\end{array}$ \\
\hline Plasmapheresis & 2 & 14.28 & 2 & 2 Organophosphates \\
\hline Hemofiltration & 1 & 7.15 & 1 & 1 Antiepileptics \\
\hline Total & 14 & 100 & 7 & \\
\hline
\end{tabular}

All patients were admitted to emergency department observation unit or emergency department intensive care unit and follow-up and treatment were started. There has never been a referral to the external center. Six cases that were followed up in intensive care unit for a long time were transferred to the anesthesiology and reanimation intensive care unit. The intensive care unit hospitalization periods of these six patients were $52,19,15,12$, 9 and 5 days, respectively, and one of these patients resulted in exitus.

\section{DISCUSSION}

Suicidal or accidental poisoning is among the most important reasons for hospital admissions for emergency services and intensive care units of hospitals. The incidence of poisoning varies between countries, ranging from $0.07 \%$ to $0.7 \%$ in developing countries and from $0.02 \%$ to $0.9 \%$ in developed countries, which is increasing every year worldwide [12-14].

When drug intoxication cases were evaluated in the literature, female patients were shown as 55.7\%, 50.5\%, 67.6\%, 67.5\% and $64 \%$ respectively [15-19]. The rate of female cases in our study was $64.2 \%$, in accordance with the literature.

While in the study of Seydaoğlu et al. [18], the mean age of the women was $23.8 \pm 9.6$ in cases of 20 years or older, in the study of Toft et al. [20] the mean age of the women was found to be $34.4 \pm 14.4$. In our study, the mean age of women was found $31.35 \pm 10.56$. The mean age of women was found to be in accordance with the literature.

When the monthly distribution of case applications made to UZEM in 2008 was evaluated, seasonal changes were observed. When we investigate the literature, it is observed that there is an increase in summer months. In the study of Baydin et al. a rate of $35.4 \%$ in summer months, and in the study of Tüfekçi et al. $31.7 \%$ of the cases were found in summer months, which shows an increase in the numbers of poisoning cases in the summer months $[21,22]$. In our study, there is no significant difference between the seasons, with the highest number of cases of poisoning in summer. Studies suggesting that there is a significant relationship between suicide and temperature, humidity and weather conditions in seasonal suicides emphasize the importance of the role of environmental factors.

Different rates of hospitalization have been reported in the literature. In the study of Demircan et al. [23] reported that 9\% of patients were hospitalized. In the study of Kavalc1 et al. [24], there is a hospitalization rate of $20.8 \%$. In the study of Akköse et al. [25], most of the cases (56.4\%) were followed up, treated and discharged from the emergency service. In various publications in our country; In the study of Ok et al., this rate was 54\% [26], 
in the study of Güloğlu et al. this rate was reported as 62\% [27]. In our study, 179 (37.1\%) cases were followed up in the emergency intensive care unit and $304(62.9 \%)$ cases were followed up in the observation unit of emergency department while the cases were never referred to other hospitals. Patients were observed for at least 24 hours and discharged at the end of the follow-up period after receiving the opinion of the psychiatrist. All patients were hospitalized, followed up in the observation unit or intensive care units.

The rates of intensive care unit hospitalization in the literature are; in the study of Beaune et al., $6 \%$ of the cases were hospitalized in the intensive care unit, 55\% were followed up in emergency services for less than 24 hours and $30 \%$ were transferred to the psychiatry department [28]. In the retrospective study of Özayar et al. [7] intensive care unit hospitalization rate was found $10.06 \%$, while in the study of Demir et al. [3] was found to be $12.96 \%$. In the 11-year population-based cohort study of Yaroon et al. [29] in which 81,675 patients were evaluated, the intensive care unit hospitalization rate was found $26.9 \%$. In the study that Güven and Türkdoğan [30] addressed cost in the cases of poisoning, $15.4 \%$ cases were hospitalized to the intensive care unit. In our study, different results were obtained from these studies (37.1\%). The difference in these rates of intensive care unit hospitalization was thought to be due to the presence of 2 intensive care units with 11 beds in our clinic, and the National Toxicology Consultation Center, which adviced us to follow up many patients in intensive care units.

Mean duration of hospitalization in Intensive care unit; in the study of Özayar et al. [7] was found 2.7 days, in the study of Cengiz et al. [31] was found 6.4 days, in the study of Yüce [11] was found 1.8 days and in the study of Kaya et al. was found 8.9 days and the length of intensive care unit hospitalization was classified according to the substances causing poisoning. The mean intensive care unit stay was found to be 10.9 days in organic phosphate-poisoned cases, 13.9 days in amitriptyline poisoned cases and 9.4 days in antidepressant poisoned cases [32]. In our study, the mean duration of hospitalization in intensive care unit was $3.21 \pm 4.5$ days, in accordance with the literature. Hospitalization period in intensive care units depends on the substance causing the poisoning, whether extracorporeal treatment and mechanical ventilation are needed.

The most commonly used drugs in drug poisoning are antidepressants. In depressive patients, suicide attempts are high and in general, it has been determined that these patients are engaged in suicide attempts with their own medicines. Surveys in this regard have shown that the cases that constitute $50 \%$ of suicide attempts are patients with previous psychiatric problems $[33,34]$. In the study of Avşaroğulları et al when the antidepressants were evaluated [35], TCA was found in 57\% and SSRI was found in $31 \%$ of the cases. In the 11-year study about antidepressants of Ünverir et al. [36] TCA was found 58.4\% and SSRIs was found in $22.5 \%$ of the cases. In the study of Demir et al. [37], classification of the antidepressant drugs used for suicide were $84,2 \%$ TCA and 9.2\% SSRIs. Our study is incompatible with the literature.
When the antidepressants were evaluated, 52 (58.4\%) cases were poisoned by SSRIs and $25(28.1 \%)$ cases were poisoned by TCA. When the literature is investigated, the incidence of toxicity with TCA decreases relatively over the years and leaves place to SSRIs in patients with depression. These medicines can be provided without prescription from pharmacies with complaints such as sleep disturbance, restlessness. As mentioned in the literature, access to TCA is easy and cheap, and due to serious side effects of TCA, we think that physicians are more careful when prescribing it.

In the United States, the rate of extracorporeal techniques used for poisoning cases according to the year 2015 was found to be $0.4 \%$ for hemodialysis and $0.007 \%$ for hemoperfusion [38]. In the 882 -patient study of Beaune et al. $2 \%$ of the patients received hemodialysis treatment [28]. Ersoy et al. stated that they performed hemodialysis at a rate of $2.5 \%$ in their study [39]. In our study, when patients were evaluated according to extracorporeal treatment, the number of patients were $14.1 .24 \%$ of the cases received hemodialysis treatment, $1.03 \%$ of the cases received hemoperfusion treatment. $85.7 \%$ of the cases in which extracorporeal treatment performed were followed up in intensive care units, 2 out of 3 exitus cases received extracorporal treatment. In the study of Pedroso and Silva, the relationship between hemodialysis and the result of poisoning was investigated and the mortality rate was $36.3 \%$ in patients who received hemodialysis treatment and $25.6 \%$ in patients who didnt receive hemodialysis treatment. Although not statistically significant (RR: 0.89 ; $95 \%$ Cl: $0.54-$ 1.35), mortality was higher in hemodialysis patients. As in other studies conducted in this study, it is thought that high mortality may be due to the necessity of hemodialysis and the severity of clinical presentation, rather than the application of hemodialysis [40].

Reasons of poisonings that result in exitus consists of a methyl alcohol, a carbamate-containing and an organophosphate-containing agent. Methyl alcohol poisoning case received hemoperfusion and organophosphate poisoning case received plasmapheresis treatments. In the case of organophosphate poisoning treated with plasmapheresis, IV lipid therapy was also applied. It has been observed that all exitus cases were poisoned by the single substance. When the cases that resulted in exitus were applied to the emergency service, the leukocyte counts were 18660 / $\mathrm{mm} 3.18730 / \mathrm{mm} 3$ and $27610 / \mathrm{mm} 3$, respectively which was above the leukocyte counts of living cases.

Our mortality was lower than the literature. Since, our emergency department has an intensive care unit, all the cases in our region are admitted to our center, extracorporeal treatment possibilities, with the help of antidotes and supportive treatments (IV Lipid etc.) we can follow up and cure these patients in the light of up to date information from admission until discharge. However, there is no adequate guidelines to decide intensive care unit hospitalization, service hospitalization and the duration of followup periods. We think that there is a need for the determination of toxicological guidelines and scoring systems that can guide clinicians. 
After all, patients with drug intoxication are young, without comorbid diseases and who can achieve satisfactory results with early treatment. The majority are with lipophilic drugs, and mortality is prevented with supportive treatments such as extracorporal therapy and intravenous lipid. For this reason, hospitals which can follow up poisoned patients should be informed and supported with equipment.

Conflict of Interests: The authors declare that they have no conflict of interest.

Financial Disclosure: No financial support was received

\section{REFERENCES}

1. Demirel İ. A Retrospective Analysis of Intoxication Cases in Intensive Care Unit of Elazığ Education and Research Hospital. Firat Med J. 2010;15:184-7.

2. Osterhoudt KC, Trevor M. Penning. "Drug toxicity and poisoning." Goodman \& Gilman's The Pharmacological Basis of Therapeutics 2011:73-87.

3. Demir G, Eren GA, Hergünsel O, Çukurova Z, Kızanlık Y. The retrograde analysis of the intoxication cases managed in our intensive care unit between 2003-2007. Med J Bakırköy 2008;4:139-43.

4. Mowry JB, Spyker DA, Brooks DE, McMillan N, Schauben JL. 2014 Annual Report of the AmericanAssociation of Poison Control Centers' National Poison Data System (NPDS): $32^{\text {nd }}$ Annual Report. ClinToxicol (Phila). 2015;53:962-1147.

5. Göksu S, Yıldırım C, Koçoğlu H, Tutak A, Öner Ü. Characteristics of acuteadult poisoning in Gaziantep, Turkey. J Toxicol \& Clin Toxicol. 2002;40:833-37.

6. Akköse Ş, Bulut M, Armağan E, Cebicci H. Acute poisoning in adults in the years 1996-2001 treated in the Uludağ University Hospital, Marmara region, Turkey. Clin Toxicol 2005;43:105-09.

7. Özayar E, Değerli S, Güleç H, Şahin Ş, Dereli N. Retrospective Analysis of Intoxication Cases in the ICU. Yoğun Bakım Derg. 2011;3:59-62.

8. Koylu R, Dundar ZD, Koylu O, et al. The Experiences in a Toxicology Unit: A Review of 623 Cases. J Clin Med Res. 2014;6:59-65.

9. Güzel IŞ, Kibar AE, Vidinlisan S. Evaluation of demographic characteristics in intoxication cases who admitted to emergency room in pediatric unit. Genel Tip Derg. 2011;21: 101-7.

10. Eddleston M. Patterns and problems of deliberate self-poisoning in the developing world. QJ Med. 2000;93;715-31.

11. Yüce HH. Retrospectıve analysis of intoxication cases who were followed up in the intensıve care unit in Giresun area. Bidder Tip Bilimleri Dergisi. 2011;3:32-5.

12. Bohnert ASB, Fudalej S, Ilgen MA. Increasing Poisoning Mortality Rates in the United States, 1999-2006. Public Health Rep. 2010;125:542-7.

13. Watson WA, Litovitz TL, Rodgers GC Jr, et al. 2004 Annual report of the American Association of Poison Control Centers toxic exposure surveillance system. Am J Emerg Med. 2005;23:589-666.

14. Hanssens Y, Deleu D, Taqi A. Etiologic and demographic characteristics of poisoning: a prospective hospital-based study in Oman. J Toxicol ClinToxicol. 2001;39:371-80.

15. Brandenburg R, Brinkman S, de Keizer NF, Kesecioglu J, Meulenbelt J, de Lange DW. The need for ICU admission in intoxicated patients: a prediction model. Clin Toxicol. 2017;55:4-11.

16. SJ Kim, SP Chung, HW Gil, et al. The poisoning information database covers a large proportion of real poisoning cases in Korea. J Korean Med Sci. 2016; 31: 1037-41
17. Pablo A, Marcela G, Eli L, et al. Medication overdoses at a public emergency department in Santiago, Chile. Western J Emerg Med. 2016;17: 75-80.

18. Seydaoğlu G, Satar S, Alparslan N. Frequency and mortality risk factors of acute adult poisoning in Adana, Turkey, 1997-2002. Mt Sinai J Med. 2005; 72: 393-401.

19. Karcıŏ̆lu Ö, Ayrık C, Tomruk Ö, Topaçoğlu H, Keleş A. Retrospective analysis of adult poisoning cases in the emergency department. O.M.Ü. Tip Dergisi. 2000; 17: 156-62.

20. Toft S, Horwitz H, Dalhoff KP. Long-term mortality after poisoning with antipsychotics, Clinical Toxicol. 2017;55:267-74.

21. Koçak R, Tanrıverdi Z, Seyrek E, Alsparslan N. Acute poisoning: A two years retrospective study. Bulletin of Çukurova Medical Faculty. 1987; 12: 381-7.

22. Tüfekçi BI, Çurgunoğlu A, Şirin F. Characteristics of acute adult poisoning cases admitted to a university hospital in İstanbul. Human \& Experimental Toxicol. 2004;23:347-51.

23. Demircan C, Kahveci F, Engindeniz Z, et al. Analysis of acute adult poisoning cases among patients admitted to the emergency department in Bursa, Turkey. Gazi Tip Derg. 2009;20:157-62.

24. Kavalcı C, Durukan P, Cevik Y, Özer M, İkizceli İ. Analyses of intoxication cases: one-year experience of a new hospital. Turk J Emerg Med. 2006;6:163-6.

25. Akköse Ş, Köksal Ö, Fedakar R, Emircan Ş, Durmuş O. Poisoning Cases in adults in the years 1996-2004. Uludağ Üniversitesi Tip Fakültesi Dergisi. 2006;32:25-7

26. Ok G, Erbüyün K, Mirzai T, Vatansever D, Tok D. The retrospective analysis of intoxications admitted to our emergency service. Toksikoloji Dergisi. 2006;4:5-9.

27. Güloğlu C, Kara IH. Acute poisoning cases admitted to university hospital emergency department in Diyarbakir, Turkey. Hum Exp Toxicol. 2005; 24: 49-54.

28. Beaune S, Juvin P, Beauchet A, Casalino E, Megarbane B. Deliberate drug poisonings admitted to an emergency department in Paris area - a descriptive study and assessment of risk factors for intensive care admission. Eur Rev Med Pharmacol Sci. 2016;20:1174-9.

29. Finkelstein $Y$, Macdonald EM, Hollands S, et al. Repetition of intentional drug overdose: a population-based study. Clinical Toxicol. 2016;54:5859 .

30. Guven FMK, Turkdogan KA, Duman A, et al. Cost analysis of different venues for treating suicide cases presented to the emergency department. Biomed Res- India. 2014;25:431-6.

31. Cengiz M, Baysal Z, Ganidağ $l_{1} \mathrm{~S}$, Altindag A. Characteristics of poisoning cases in adult intensive care unit in Sanliurfa, Turkey. Saudi Med J. 2006;27:497-502.

32. Kaya S, Kararmaz A, Karaman H, Turhanoğlu S. The Retrospective Analysis of the Poisoning Cases in Intensive Care Unit. Dicle Tip Derg. 2006;33:242-4.

33. Beskow J. Depression and suicide. Pharmacopsychiatry 1990;23:3-8.

34. Cheng AT. Mental illness and suicide. A case-control study in East Taiwan. Arch Gen Psych. 1995; 52: 594-603.

35. Avşaroğulları L, Senol V, Akdur O, Akin A, Durukan P, Özkan S. Characteristics of acute adult poisoning in a univercity hospital emergency department in central Turkey: a three-year analysisi. J Pak Med Assoc. 2012;62:129-33

36. Unverir P, Atilla R, Karcioglu O, Topacoglu H, Demiral Y, Tuncok Y. A retrospective analysis of antidepressant poisonings in the emergency department: 11-year experience. Human \& Experimental Toxicol. 2006; 25: $605-12$ 
37. Mowry JB, Spyker DA, Brooks DE, Zimmerman A, Schauben JL. 2015 Annual Report of the American Association of Poison Control Centers' National Poison Data System (NPDS): 33rd Annual Report, Clinical Toxicology. 2016; 54:924-1109.

38. Ersoy A, Kara D, Cangir CC, Erdoğan E, Ali A, Büyükyıldırım A. Evaluating intoxicated patients in intensive care unit. Okmeydanı Tip Dergisi. 2013; 29: 72-5.
39. Pedroso JA, Silva CA. The nephrologist as a consultant for acute poisoning: epidemiology of severe poisonings in the State of Rio Grande do Sul and techniques to enhance renal elimination. J Bras Nefrol. 2010; 32: $340-8$. 